\title{
Survey of calcium supplementation to prevent preeclampsia: the gap between evidence and practice in Brazil
}

\author{
Erika Barbosa Camargo ${ }^{1}$, Luci Fabiane Scheffer Moraes ${ }^{2}$, Celsa Moura Souza ${ }^{3}$, Rita Akutsu', Jorge Maia Barreto ${ }^{5}$, \\ Edina Mariko Koga da Silva', Ana Pilar Betrán ${ }^{6}$ and Maria Regina Torloni ${ }^{*}$
}

\begin{abstract}
Background: Preeclampsia is a major cause of maternal and perinatal morbidity and mortality worldwide and especially in Latin America. High quality evidence indicates that calcium supplementation during pregnancy significantly reduces the incidence of preeclampsia and its consequences, including severe maternal morbidity and death. Few studies have assessed the implementation of this intervention in clinical practice. The study aimed to assess the proportion of pregnant women who received calcium supplements in Brazilian public antenatal care clinics.

Methods: This cross-sectional study interviewed women waiting for antenatal care visits in 9 public clinics in 4 Brazilian cities in 2010-2012. Trained interviewers used a standardized anonymous questionnaire to collect socio demographic and obstetric data, information on ingestion of dairy products and on prescriptions received during current pregnancy.

Results: A total of 788 valid questionnaires were analyzed. Participants were young (mean age 25.9), mostly multiparous $(71.3 \%)$ and in the $2^{\text {nd }}$ or $3^{\text {rd }}$ trimesters of pregnancy at the time of interview (87.6\%). Only $5.1 \%$ (40/788) had received a prescription for calcium supplements. Based on their reported ingestion of dairy products, the mean daily dietary calcium intake of the participants was 210 (+ 265) mg/day and over 90\% consumed less than $1 \mathrm{~g}$ of calcium/day.

Conclusions: Despite good quality evidence indicating the benefits of this practice especially for women with low calcium diets, less than $6 \%$ of a sample of women receiving antenatal care in Brazilian public clinics received a prescription for calcium supplements. There is an urgent need to upscale the implementation of this life-saving intervention.
\end{abstract}

Keywords: Preeclampsia, Eclampsia, Calcium, Dietary supplements, Primary prevention, Calcium dietary, Developing countries

\section{Background}

Each year, almost 60,000 women die in the world due to hypertensive disorders of pregnancy [1]. Hypertension is the leading cause of maternal mortality (MM) in Latin America [2,3]. According to the latest national estimates, pre-eclampsia (PE) and eclampsia (E) are the single largest contributors to the MM rate of Brazil, accounting for

\footnotetext{
* Correspondence: ginecologia@terra.com.br

${ }^{1}$ Internal Medicine Department, São Paulo Federal University (UNIFESP), São Paulo, Brazil

Full list of author information is available at the end of the article
}

approximately $20 \%$ of all maternal deaths in that country [4]. Hypertensive disorders are also a major cause of elective preterm births as well as perinatal morbidity and mortality [5-7]. Each year, the Brazilian public health system spends over \$14 million US dollars in direct costs for the treatment of $\mathrm{PE} / \mathrm{E}$, a substantial expenditure for a developing country [8].

$\mathrm{PE}$, defined as hypertension and proteinuria with onset in the $2^{\text {nd }}$ half of pregnancy [9], affects $6-10 \%$ of all pregnant women and $2-8 \%$ of them will develop severe forms of the disease including eclampsia, characterized

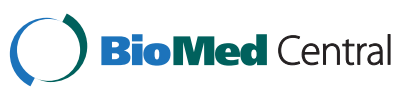


by the appearance of seizures [10]. Although the pathogenesis of PE is not yet completely understood, existing evidence indicates that the main initiating events are placental hypoperfusion, increased production of inflammatory and anti-angiogenic mediators, followed by systemic endothelial damage, disseminated vasospasm, generalized tissue hypoperfusion and aggravation of placental ischemia, thus perpetuating the vicious cycle [11-14]. Currently there is no effective treatment for $\mathrm{PE} / \mathrm{E}$ and delivery is the only option to halt the disease process [15].

Over 30 years ago, observational studies identified an inverse relationship between maternal calcium (Ca) intake and the incidence of PE $[16,17]$. Based on these findings, a series of randomized controlled trials (RCT) were carried out to evaluate the effectiveness of Ca supplementation in the prevention of PE [18-20]. Over the last 15 years, several systematic reviews pooled the results of these trials, showing the benefits of this intervention [21-24]. According to a systematic review of individual data from 12 RCTs which included over 15,000 participants, Ca supplementation starting in the $2^{\text {nd }}$ trimester of pregnancy reduces the risk of developing PE by $64 \%$ and the risk of MM or severe maternal morbidity by $20 \%$, in women with low dietary $\mathrm{Ca}$ intake, defined as less than $900 \mathrm{mg} /$ day [25]. In 2011 the World Health Organization (WHO) recognized Ca supplementation during pregnancy as an effective intervention to prevent PE and to reduce $\mathrm{MM}$ and recommended that women with low dietary intake or at high risk for PE should receive 1.5-2.0 g of Ca daily, starting in the $2^{\text {nd }}$ trimester [26].

$\mathrm{PE}$ is associated with a large burden of morbidity and mortality in low-resource settings, especially in Latin America, and there is a body of high quality evidence indicating the potential benefits of $\mathrm{Ca}$ supplementation in pregnancy; yet the actual implementation of this intervention into clinical practice has not been extensively investigated. In 2010 Silva et al. interviewed 250 high-risk pregnant or post-partum Brazilian women and reported that only $10 \%$ of them had received prescriptions for $\mathrm{Ca}$ supplements during pregnancy [27]. We identified no other publications assessing the antenatal prescription of $\mathrm{Ca}$ to prevent PE. Our main objective was to assess the proportion of women who received a prescription of $\mathrm{Ca}$ supplements during pregnancy in a sample of Brazilian public healthcare clinics.

\section{Methods}

This cross-sectional study interviewed women receiving antenatal care in the public Brazilian healthcare system. The interviews were performed between October 2010 and June 2012 in nine public healthcare clinics located in four cities in different geographic regions of Brazil: Coari (Amazonas state, north region, 3 clinics), Brasília
(Federal District, central region, 1 clinic), Piripiri (Piauí state, central region, 3 clinics) and Tubarão (Santa Catarina state, southern region, 2 clinics).These clinics offered free antenatal care to the general obstetric population, i.e. mostly low and medium risk pregnant women. The Brazilian national health system offers free antenatal care to all women in the country and recommends the use of folic acid and iron supplements to all pregnant women. There is no national guideline on other supplements during pregnancy. Calcium carbonate tablets containing $500 \mathrm{mg}$ of elemental $\mathrm{Ca}$ are distributed free of charge by the national health system and dispensed locally in any public healthcare center, to all patients who have a medical prescription for this supplement.

Pregnant women carrying a live fetus, of any parity and gestational age, booked for antenatal care at one of the selected centers, and capable of answering an oral questionnaire were considered eligible to participate. Women waiting for their $1^{\text {st }}$ antenatal care visit were excluded. Interviewers approached the women in the waiting rooms of the health facilities during morning periods, explained the objectives of the study and invited them to participate. Participants who fulfilled the selection criteria and agreed to participate were asked to sign an informed consent form and then interviewed using a standardized oral questionnaire. The questionnaire was designed and tested by the authors and consisted of close and open-ended questions to collect information on socio demographic characteristics, obstetric history, current pregnancy, usual dairy intake and medical prescriptions received so far, including $\mathrm{Ca}$ supplementation. The question on dairy consumption asked participants what was their current usual intake of milk, cheese or other milk products. The Brazilian food composition table [28] was used to estimate the amount of dietary $\mathrm{Ca}$ ingested by the participants based on their consumption of dairy products. Dairy intake was converted to estimated $\mathrm{Ca}$ intake based on the reported ingestion of milk (one $200 \mathrm{ml}$ cup $=246 \mathrm{mg} \mathrm{Ca}$ ) and cheese (one $30 \mathrm{~g}$ slice $=282 \mathrm{mg} \mathrm{Ca}$ ). To assess the adequacy of $\mathrm{Ca}$ intake, the latest recommendations of the Dietary Reference Intakes - DRI were used $[29,30]$. According to these recommendations, adult pregnant women should have a daily $\mathrm{Ca}$ ingestion of $1,000 \mathrm{mg}$ and pregnant adolescents (14-18 years) should have a daily ingestion of $1,300 \mathrm{mg}$. Pregnant women with an average Ca intake $<900 \mathrm{mg} /$ day are classified as having a low dietary intake of $\mathrm{Ca}$ [25].

The interviews were anonymous, lasted an average of 10 minutes and were conducted individually and privately. Participants were encouraged to check their antenatal care booklet, which was in their hands at the time of the interview, to confirm information given to the interviewer. Women were informed that they could decline to answer 
any question. Questionnaires with more than five unanswered questions were excluded from the analyses.

The interviewers were three medical students and nine nutrition undergraduates who were specifically trained for this study. The interviewers collected data daily during an average of five weeks in each of the participating clinics.

Sample size was calculated using the frequency of Ca prescription reported by Silva 2010 [27] of 10\%. With an absolute error of $2.5 \%$ and a significance level of $5 \%$, a sample of 553 participants was calculated. Considering possible losses, the planned sample was 800 participants. The cities and public healthcare clinics included in the study were selected as a convenience sample.

The completed questionnaires were sent by mail to the first author who entered the data into an electronic database. Results are presented descriptively as frequencies and percentages for categorical variables, and as means and standard deviation (SD) for continuous variables. Relevant outcomes are presented with their 95\% confidence intervals $(\mathrm{CI})$.

Participants were divided in two subgroups according to their risk for PE, based on widely accepted parameters [31-34]. Participants with any of the following characteristics were considered at high risk for PE: nulliparas, women $<20$ or $>35$ years, diabetics (type 1 or 2 ) or women with a history of hypertension in a previous pregnancy. All other participants, i.e. those without any of the previous characteristics, were classified as being at low risk for PE. We analyzed possible differences in the rate of Ca prescription between these two groups using the Chi square test. $\mathrm{P}$ values $<0.05$ were considered significant. The software SPSS version $1.6\left(\mathrm{IBM}^{\circ} \mathrm{SPSS}^{\circ}\right.$, Chicago, U.S.A) was used for analyses.

The study was approved by São Paulo Federal University's ethics committee and all participants provided free informed consent. The study complies with the ethical principles of the Helsinki declaration.

\section{Results}

A total of 832 eligible women were invited to participate and 32 declined. Of the 800 who agreed to answer the questionnaire, 12 refused to answer five or more questions and were excluded from the study, resulting in 788 valid questionnaires included in the final analyses. Table 1 presents the main characteristics of the participants. Age ranged from 13 to 42 years and $17.6 \%$ were adolescents. Most participants were living with a partner (82.1\%), multiparous (71.3\%) and reported that the current pregnancy had not been planned (56\%). Nearly $90 \%$ of participants were interviewed in the $2^{\text {nd }}$ or $3^{\text {rd }}$ trimesters of pregnancy and almost half of them had attended at least five antenatal visits at the time of the interview. A total of 51 women $(6.5 \%)$ smoked and $61(7.7 \%)$ consumed alcohol
Table 1 Main characteristics and dietary calcium intake of 788 Brazilian pregnant women

\begin{tabular}{lcc}
\hline Variable & Values $^{1}$ & \\
\hline Age, years & 25.9 & $(6.3)$ \\
Marital status & & \\
$\quad$ Married or living with partner & 647 & $(82.1)$ \\
$\quad$ Single & 127 & $(16.1)$ \\
$\quad$ Separated/divorced & 14 & $(1.8)$ \\
Parity & & \\
0 & 226 & $(28.7)$ \\
$\quad 1$ & 245 & $(31.1)$ \\
2 or + & 317 & $(40.2)$ \\
Unplanned pregnancy & 440 & $(55.8)$ \\
Gestational age at the time of the interview & & \\
$\quad$ Mean (SD), weeks & 24.3 & $(8.3)$ \\
$1^{\text {st }}$ trimester & 98 & $(12.4)$ \\
$2^{\text {nd }}$ trimester & 315 & $(40.0)$ \\
$3^{\text {rd }}$ trimester & 375 & $(47.6)$
\end{tabular}

Number of antenatal care visits up to the moment

$\begin{array}{lll}1 & 112 & (14.2) \\ 2 \text { to } 4 & 314 & (39.9) \\ 5 \text { or }+ & 362 & (45.9) \\ \text { men at high risk for } \mathrm{PE}^{*} & 250 & \text { (31.7) }\end{array}$

\section{Current milk intake (cups/day)}

$0 \quad 189-(24.0)$

$1(246 \mathrm{mg})^{2} \quad 282 \quad$ (35.8)

$2-3(492 \mathrm{mg}-738 \mathrm{mg}) \quad 267 \quad(33.9)$

4 or $+(984 \mathrm{mg}$ or +$)$

Current cheese intake

$\begin{array}{lcc}\text { Up to } 1 \text { portion }{ }^{3} / \text { day } & 130 & \text { (16.5) } \\ \text { Up to } 1 \text { portion/week } & 199 & \text { (25.3) } \\ \text { Up to } 1 \text { portion/month } & 50 & \text { (6.3) } \\ \text { Rarely }^{4} \text { or never } & 409 & \text { (51.9) }\end{array}$

*Any of the following: nulliparity, age $<20$ or $>35$ years, diabetes mellitus or history of hypertension in a previous pregnancy.

${ }^{1}$ All values expressed as mean (SD) or $\mathrm{N}(\%)$.

${ }^{2}$ Equivalent calcium value.

${ }^{3}$ One portion is $30 \mathrm{~g}$ of cheese.

${ }^{4}$ Less than one portion per month.

at least once a week. A total of 250 (31.7\%) women were classified as being at high risk for PE, the main factor was nulliparity.

Approximately $60 \%$ of the women reported that they drank only up to one cup of milk ( $246 \mathrm{mg} \mathrm{Ca}$ ) daily, while only $6.3 \%$ drank four or more cups of milk daily (95\% CI 4.8\% - 8.2\%). Over half of the participants never or rarely (less than once a month) ate cheese. The ingestion of other dairy products (including yogurt, sour cream or cream spreads) was even less frequent, with $79 \%$ (622) 
of the women reporting that these were consumed less than once a month. Only 3\% (4/139) of the adolescents included in the survey drank four or more cups of milk per day $(984 \mathrm{mg} \mathrm{Ca}$ ) and $58.2 \%$ reported that they rarely or never ate cheese. Based on their reported ingestion of dairy products, the mean daily dietary $\mathrm{Ca}$ intake of the 788 participants was $210( \pm 265) \mathrm{mg}$ and over $90 \%$ consumed less than $1 \mathrm{~g}$ of $\mathrm{Ca} /$ day. The mean daily dietary $\mathrm{Ca}$ intake from dairy products reported by adolescents was 313 ( \pm 262$) \mathrm{mg}$.

Less than $6 \%(\mathrm{~N}=40)$ of the participants $(95 \%$ CI $3.7 \%$ $6.8 \%)$ reported that they had received a prescription for Ca supplements during their current pregnancy (Table 2). There were no significant differences in the women at high versus low risk for PE (5.2\% versus $5.0 \%$, respectively). Most (60\%) of the 40 women who had received a Ca prescription did not know the reasons for this supplementation; only three reported to have been told that these tablets were to prevent problems related to high blood pressure. Approximately one third of the participants $(\mathrm{N}=252)$ had been advised by their physician to increase the ingestion of dairy products during pregnancy. Over half $(144 / 252)$ of these women received instructions to drink a total of 1-2 glasses of milk/day,

Table 2 Calcium prescription and advice on the ingestion of dairy products received by 788 Brazilian pregnant women

\begin{tabular}{|c|c|c|}
\hline & & lues \\
\hline & $\mathbf{N}$ & (\%) \\
\hline Did physician prescribe cal & & \\
\hline Yes & 40 & (5.1) \\
\hline No & 694 & $(88.1)$ \\
\hline Unsure/Doesn't know & 54 & (6.8) \\
\hline $\begin{array}{l}\text { Did physician explain the } \\
\text { prescription? }\end{array}$ & & \\
\hline Yes & 16 & $(40.0)$ \\
\hline No & 24 & $(60.0)$ \\
\hline Reason for calcium prescri & & \\
\hline For bones (baby or mother) & 10 & $(62.5)$ \\
\hline For blood pressure & 3 & (18.8) \\
\hline Calcium deficiency & 2 & $(12.5)$ \\
\hline Anemia & 1 & (6.3) \\
\hline Did physician tell you to e & & \\
\hline Yes & 252 & (32.0) \\
\hline No & 536 & $(68.0)$ \\
\hline Recommendations given $b$ & & \\
\hline Drink $1-2$ cups of milk/day & 144 & $(57.1)$ \\
\hline Drink 3-4 cups of milk/day & 10 & $(4.0)$ \\
\hline Unclear/did not specify & 98 & (38.9) \\
\hline
\end{tabular}

${ }^{2}$ Over total answering Yes to previous question. while approximately $40 \%(98 / 252)$ informed that their doctor had not been clear about the type and quantity of dairy product that they should consume daily (Table 2). Overall, less than $1 \%$ of the participants $(4 / 788)$ were encouraged to consume enough dairy products to attain international DRIs for pregnant women.

\section{Discussion}

Less than $6 \%$ of almost 800 women receiving antenatal care in nine public Brazilian healthcare clinics were given a prescription of $\mathrm{Ca}$ supplements during pregnancy and most of them did not know why they were taking it. Additionally, based on their reported dairy product ingestion, over $90 \%$ of the participants consumed less than $1 \mathrm{~g} \mathrm{Ca}$ /day. Less than one third of the women informed that their physicians had told them to increase the ingestion of these products during pregnancy and when they did, in over $95 \%$ of the cases, the recommendations did not comply with minimum DRIs for pregnancy.

Although our main objective was not to estimate dietary intake of $\mathrm{Ca}$ by pregnant women, the participants' average dietary $\mathrm{Ca}$ intake from dairy products was less than $400 \mathrm{mg} /$ day. Given that milk products were the only food items included in the questionnaire, the actual daily $\mathrm{Ca}$ intake of these women was probably higher than this, although it is unlikely that it would be close to the $1 \mathrm{~g} /$ day recommended for pregnancy. According to the latest national food inquiry survey, the mean dietary Ca intake of adult Brazilian women (19-59 years) is only $438 \mathrm{mg} /$ day and $90.7 \%$ of them do not reach the recommended dietary calcium intake for their age [35]. According to this same survey, dairy products are the main source of dietary $\mathrm{Ca}$ for Brazilian adults. Only a few, small studies have assessed the $\mathrm{Ca}$ ingestion of Brazilian pregnant women and they focused on specific groups, such as overweight and adolescent participants. According to these studies, mean daily Ca intakes ranged from $586.6 \mathrm{mg}$ to $842.9 \mathrm{mg} /$ day [36-38]. This low dietary Ca intake is typical of diets in Latin America and Asia [39-41] and contrasts with the daily $1200 \mathrm{mg} \mathrm{Ca}$ /day of American [42] and European pregnant women [43,44], with some exceptions [45].

The only other study that evaluated Ca prescription to prevent PE was also carried out in Brazil and reported that $10 \%$ of 250 women at high risk for PE had received Ca supplements during pregnancy [27]. The somewhat higher proportion of women receiving Ca supplementation in that study could be attributed to the fact that those investigators interviewed exclusively high-risk women managed in tertiary teaching university hospitals.

This study had several strong points. To the best of our knowledge, it is the largest study to analyze Ca supplementation during pregnancy to prevent PE. In addition, data collection followed rigorous methodology using a 
standardized anonymous questionnaire and trained interviewers. However, we acknowledge that the assessment of dietary Ca could have been more complete if we had collected information on the ingestion of other non-dairy sources of Ca. A limitation of this study was the use of a convenience sample. However, the main characteristics of our participants are similar to the general population of Brazilian reproductive age women reported in a recent national survey on maternal and child health [46]. Nevertheless, the results of this survey cannot be generalized to other settings or countries. Although our sample most likely over-represented urban women, it would be expected that the dietary $\mathrm{Ca}$ intake of pregnant rural women would be even lower, as suggested by the latest national inquiry on food habits [35]. Finally, as with any other patient survey, the data analyzed were based exclusively on the answers given by the participants and are therefore subject to recall bias [47] and do not necessarily reflect the exact practice of the physicians. Future studies should interview health professionals involved in prenatal care, to assess their knowledge, attitude and practice regarding $\mathrm{Ca}$ supplementation during pregnancy, in order to identify the main facilitators and barriers to upscale the implementation of this intervention.

Our findings indicate that Brazilian doctors working in the public health system do not routinely prescribe $\mathrm{Ca}$ to their pregnant patients, despite the free availability of these supplements in the public health system. This is possibly due to their lack of knowledge about the benefits of Ca supplementation to prevent PE. Besides the need for continued medical education of these professionals, the guidelines currently used in the country's public health care system need to be reviewed and updated, to encourage the use of this, as well as other evidence-based interventions for maternal health. Besides the evident benefits of $\mathrm{Ca}$ supplementation for the individual patients and their families, decreasing the number of cases of $\mathrm{PE} / \mathrm{E}$ can also have significant cost saving implications for the national public health system.

Most of the research to date has focused on supplementation starting in the $2^{\text {nd }}$ trimester of pregnancy and although current evidence supports Ca supplementation during pregnancy for the prevention of $\mathrm{PE}$, it has been hypothesized that the effect could be even more dramatic if supplementation started earlier. WHO is currently coordinating a multi-country randomized trial to assess if periconceptional $\mathrm{Ca}$ supplementation reduces the incidence of recurrent PE more effectively than supplementation starting in the $2^{\text {nd }}$ trimester [48]. Results of this trial may increase the value of $\mathrm{Ca}$ supplementation in the future.

Despite existing WHO evidence-based recommendations indicating that $\mathrm{Ca}$ supplementation in pregnancy is beneficial for women with low dietary Ca intake, our study indicates that this intervention is not being used in the daily practice of public healthcare clinics in Brazil. This finding is not unexpected since the gap between good evidence and implementation is common in the history of obstetric practice. For example, several decades passed between the publication of systematic reviews pointing that antenatal corticosteroids significantly reduced mortality and morbidity of premature babies, before this intervention was widely implemented worldwide [49]. Similarly, it took almost a century, during which thousands of unnecessary maternal deaths occurred, until magnesium sulfate became widely used for the prevention and treatment of eclampsia [50].

Implementation of evidence-based obstetrical practice remains a challenge. Time, as well as political determination, strategic efforts, financial and human resources are necessary to transform good evidence into good clinical practice. Investments in implementation research are also needed to develop strategies that will help to reduce the still ubiquitous large gap between evidence and practice.

\section{Conclusions}

Ca supplementation is given to less than $6 \%$ of women receiving antenatal care in a sample of public clinics in Brazil. Strategic efforts are needed to enhance the implementation of this evidence-based intervention. Upscaling this practice could lead to a significant reduction in the incidence of $\mathrm{PE} / \mathrm{E}$, reducing associated maternal and perinatal morbidity and mortality as well as costs for the Brazilian public health system.

\section{Abbreviations}

Ca: Calcium; Cl: Confidence interval; DRI: Daily recommended intakes; E: Eclampsia; PE: Preeclampsia; RCT: Randomized clinical trial; SD: Standard deviation; WHO: World Health Organization.

\section{Competing interests}

All authors declare that they have no competing interests.

\section{Authors' contributions}

EBC designed the study, supervised data collection, performed analyses and interpretations and drafted the manuscript. LFSM, CMS, RA and JB supervised data collection, participated in data analyses and interpretation. EMKS conceived and designed the study, performed analyses and was involved in revising the manuscript critically for important intellectual content. APB contributed to interpretation and analyses of data and was involved in revising the manuscript critically for important intellectual content. MRT performed analyses and interpretations and drafted the manuscript. All authors read and approved the final manuscript.

\section{Acknowledgements}

We thank CAPES (Brazil) for the scholarship to Camargo EB. We are grateful to Mariá Genovez Knabben Amado, Fernanda Carolina Branco, Rodrigo Ramos, Isabela Duarte, Kaliny de Souza Lira, Eline Ramos de Souza, Janayla Bruna Oliveira, Eduardo Faustino Coelho de Sousa and Taís Senna Pires for their participation in data collection.

\section{Author details}

'Internal Medicine Department, São Paulo Federal University (UNIFESP), São Paulo, Brazil. ${ }^{2}$ Physical Activity and Health Research Laboratory, South Santa Catarina University (UNISUL), Tubarão, Santa Catarina, Brazil. ${ }^{3}$ Public Health Department, Amazonas Federal University (UFAM), Manaus, Amazonas, Brazil. 
${ }^{4}$ Nutrition Department, Brasília Federal University (UnB), Brasília, Brazil. ${ }^{5}$ Federal University of Piauí, Teresina, Piauí, Brazil. ${ }^{6}$ Department of Reproductive Health and Research, World Health Organization, Geneva, Switzerland.

Received: 5 July 2013 Accepted: 28 October 2013 Published: 11 November 2013

\section{References}

1. Clark SL, Belfort MA, Dildy GA, Herbst MA, Meyers JA, Hankins GD: Maternal death in the 21st century: causes, prevention, and relationship to cesarean delivery. Am J Obstet Gynecol 2008, 199:36-5.

2. Betran AP, Wojdyla D, Posner SF, Gulmezoglu AM: National estimates for maternal mortality: an analysis based on the WHO systematic review of maternal mortality and morbidity. BMC Public Health 2005, 5:131.

3. Khan KS, Wojdyla D, Say L, Gulmezoglu AM, Van Look PF: WHO analysis of causes of maternal death: a systematic review. Lancet 2006, 367:1066-1074.

4. Saúde Brasil 2011: Uma análise da situação de saúde e a vigilância da saúde da mulher. In Brazilian Ministry of Health. Edited by Editora do Ministério da Saúde. Brasilia: Ministério da Saúde/SVS/DASS; 2012:444.

5. Langenveld J, Ravelli AC, Van Kaam AH, van der Ham DP, Van Pampus MG Porath $\mathrm{M}$, et al: Neonatal outcome of pregnancies complicated by hypertensive disorders between 34 and 37 weeks of gestation: a 7 year retrospective analysis of a national registry. Am J Obstet Gynecol 2011, 205:540-547.

6. Ozkan H, Cetinkaya M, Koksal N, Ozmen A, Yildiz M: Maternal preeclampsia is associated with an increased risk of retinopathy of prematurity. J Perinat Med 2011, 39:523-527.

7. Yucesoy G, Ozkan S, Bodur H, Tan T, Caliskan E, Vural B, et al: Maternal and perinatal outcome in pregnancies complicated with hypertensive disorder of pregnancy: a seven year experience of a tertiary care center. Arch Gynecol Obstet 2005, 273:43-49.

8. Brazilian Ministry of Health: Dados Sistema de informação ambulatorial e Sistema de informação hospitalar entre 2008-2010. DATASUS; 2011. http://www.datasus.gov.br.

9. Report of the national high blood pressure education program working group on high blood pressure in pregnancy. Am J Obstet Gynecol 2000, 183:S1-S22.

10. Sibai BM: Diagnosis, prevention, and management of eclampsia. Obstet Gynecol 2005, 105:402-410.

11. Kanasaki K, Kalluri R: The biology of preeclampsia. Kidney Int 2009, 76:831-837.

12. Meekins JW, Pijnenborg R, Hanssens M, McFadyen IR, Van AA: A study of placental bed spiral arteries and trophoblast invasion in normal and severe pre-eclamptic pregnancies. Br J Obstet Gynaecol 1994, 101:669-674.

13. Pijnenborg R, Anthony J, Davey DA, Rees A, Tiltman A, Vercruysse L, et al. Placental bed spiral arteries in the hypertensive disorders of pregnancy. Br J Obstet Gynaecol 1991, 98:648-655.

14. Wang A, Rana S, Karumanchi SA: Preeclampsia: the role of angiogenic factors in its pathogenesis. Physiology Bethesda 2009, 24:147-158.

15. Ciantar E, Walker JJ: Pre-eclampsia, severe pre-eclampsia and hemolysis, elevated liver enzymes and low platelets syndrome: what is new? Womens Health (Lond Engl) 2011, 7:555-569.

16. Belizan JM, Villar J: The relationship between calcium intake and edemaproteinuria-, and hypertension-getosis: an hypothesis. Am J Clin Nutr 1980, 33:2202-2210

17. Belizan JM, Villar J, Repke J: The relationship between calcium intake and pregnancy-induced hypertension: up-to-date evidence. Am J Obstet Gynecol 1988, 158:898-902

18. Belizan JM, Villar J, Gonzalez L, Campodonico L, Bergel E: Calcium supplementation to prevent hypertensive disorders of pregnancy. N Engl J Med 1991, 325:1399-1405.

19. Crowther CA, Hiller JE, Pridmore B, Bryce R, Duggan P, Hague WM, et al: Calcium supplementation in nulliparous women for the prevention of pregnancy-induced hypertension, preeclampsia and preterm birth: an Australian randomized trial. FRACOG and the ACT Study Group. Aust N Z J Obstet Gynaecol 1999, 39:12-18,

20. Villar J, Abdel-Aleem H, Merialdi M, Mathai M, Ali MM, Zavaleta N, et al: World Health Organization randomized trial of calcium supplementation among low calcium intake pregnant women. Am J Obstet Gynecol 2006, 194:639-649.

21. Bucher HC, Guyatt GH, Cook RJ, Hatala R, Cook DJ, Lang JD, et al: Effect of calcium supplementation on pregnancy-induced hypertension and preeclampsia: a meta-analysis of randomized controlled trials. JAMA 1996, 275:1113-1117.

22. Hofmeyr GJ, Lawrie TA, Atallah AN, Duley L: Calcium supplementation during pregnancy for preventing hypertensive disorders and related problems. Cochrane Database Syst Rev 2010, 4(8):CD001059.

23. Imdad A, Jabeen A, Bhutta ZA: Role of calcium supplementation during pregnancy in reducing risk of developing gestational hypertensive disorders: a meta-analysis of studies from developing countries. BMC Public Health 2011, 11(3):S18.

24. Zerfu TA, Ayele HT: Micronutrients and pregnancy; effect of supplementation on pregnancy and pregnancy outcomes: a systematic review. Nutr J 2013, 12:20.

25. Hofmeyr GJ, Duley L, Atallah A: Dietary calcium supplementation for prevention of pre-eclampsia and related problems: a systematic review and commentary. BJOG 2007, 114:933-943.

26. WHO: World Health Organization. In Recommendations for Prevention and Treatment of pre-eclampsia and eclampsia. Edited by World Health Organization. Geneva, Switzerland: World Health Organization; 2011. http://whqlibdoc.who.int/publications/2011/9789241548335_eng.pdf.

27. Silva CA, Silva CA, Atallah AN, Sass N, Mendes ET, Peixoto S: Evaluation of calcium and folic acid supplementation in prenatal care in Sao Paulo. Sao Paulo Med J 2010, 128:324-327.

28. NEPA-UNICAMP: Tabela brasileira de composição de alimentos, $4 a$ edição. Núcleo de Estudos e Pesquisas em Alimentação - NEPA. 2011. Campinas, Brazil, NEPAUNICAMP; 2011. http://www.unicamp.br/nepa/taco/tabela.php?ativo=tabela.

29. Hacker AN, Fung EB, King JC: Role of calcium during pregnancy: maternal and fetal needs. Nutr Rev 2012, 70:397-409.

30. National Academy of Sciences: Dietary Reference Intakes for Calcium and Vitamin D. Institute of Medicine of the National Academies (IMNA); 2011. http://www.nap.edu.

31. Duckitt K, Harrington D: Risk factors for pre-eclampsia at antenatal booking: systematic review of controlled studies. BMJ 2005, 330:565

32. Luo ZC, An N, Xu HR, Larante A, Audibert F, Fraser WD: The effects and mechanisms of primiparity on the risk of pre-eclampsia: a systematic review. Paediatr Perinat Epidemiol 2007, 21(Suppl 1):36-45.

33. Odegard RA, Vatten LJ, Nilsen ST, Salvesen KA, Austgulen R: Risk factors and clinical manifestations of pre-eclampsia. BJOG 2000, 107:1410-1416.

34. Sibai BM, Ewell M, Levine RJ, Klebanoff MA, Esterlitz J, Catalano PM, et al: Risk factors associated with preeclampsia in healthy nulliparous women. The Calcium for Preeclampsia Prevention (CPEP) Study Group. Am J Obstet Gynecol 1997, 177:1003-1010.

35. Pesquisa de orçamentos familiares 2008-2009: In Análise do consumo alimentar pessoal no Brasil. Edited by IBGE. Rio de Janeiro, Brazil: Instituto Brasileiro de Geografia e Estatística - IBGE. 2011; 2011. http://www.ibge.gov.br/home/ estatistica/populacao/condicaodevida/pof/2008_2009_analise_consumo/ pofanalise_2008_2009.pdf.

36. Azevedo DV, Sampaio HAC: Food consumption of pregnant adolescents assisted by prenatal service. Rev Nutr Campinas 2003, 16:273-280.

37. Fazio ES, Nomura RM, Dias MC, Zugaib M: Dietary intake of pregnant women and maternal weight gain after nutritional counseling. Rev Bras Ginecol Obstet 2011, 33:87-92.

38. Nascimento E, Souza SB: Evalutation of diet of overweight pregnant women. Rev Nutr Campinas 2002, 15:173-179.

39. Chen H, Wang P, Han Y, Ma J, Troy FA, Wang B: Evaluation of dietary intake of lactating women in China and its potential impact on the health of mothers and infants. BMC Womens Health 2012, 12:18.

40. Newman V, Norcross W, McDonald R: Nutrient intake of low-income Southeast Asian pregnant women. J Am Diet Assoc 1991, 91:793-799.

41. Sukchan P, Liabsuetrakul T, Chongsuvivatwong V, Songwathana P, Sornsrivichai V, Kuning M: Inadequacy of nutrients intake among pregnant women in the deep south of Thailand. BMC Public Health 2010, 10:572

42. Mikode MS, White AA: Dietary assessment of middle-income pregnant women during the first, second, and third trimesters. J Am Diet Assoc 1994, 94:196-199.

43. Ortega RM, Gaspar MJ, Moreiras O: Dietary assessment of a pregnant Spanish women group. Int J Vitam Nutr Res 1994, 64:130-134. 
44. Rolland-Cachera MF, Bellisle F, Deheeger M: Nutritional status and food intake in adolescents living in Western Europe. Eur J Clin Nutr 2000, 54(Suppl 1):S41-S46

45. Giddens JB, Krug SK, Tsang RC, Guo S, Miodovnik M, Prada JA: Pregnant adolescent and adult women have similarly low intakes of selected nutrients. J Am Diet Assoc 2000, 100:1334-1340.

46. Pesquisa Nacional de Demografia e Saúde da criança e da mulher - PNDS 2006: In Dimensões do processo reprodutivo e da saúde da criança. Edited by Ministério da Saúde B. Brasilia, Brasil: Brazilian Ministry of Health. 2009; 2009. http://bvsms.saude.gov.br/bvs/publicacoes/pnds_crianca_mulher.pdf.

47. Coughlin SS: Recall bias in epidemiologic studies. J Clin Epidemiol 1990, 43:87-91.

48. Hofmeyr GJ: Protocol 11PRT/4028: Long term calcium supplementation in women at high risk of pre-eclampsia: a randomised, placebo-controlled trial (PACTR201105000267371). Lancet; 2011. http://www.thelancet.com/protocolreviews/11PRT-4028.

49. Mwansa-Kambafwile J, Cousens S, Hansen T, Lawn JE: Antenatal steroids in preterm labour for the prevention of neonatal deaths due to complications of preterm birth. Int J Epidemiol 2010, 39(1):i122-i133.

50. Duley L: Evidence and practice: the magnesium sulphate story. Best Pract Res Clin Obstet Gynaecol 2005, 19:57-74.

doi:10.1186/1471-2393-13-206

Cite this article as: Camargo et al:: Survey of calcium supplementation to prevent preeclampsia: the gap between evidence and practice in Brazil. BMC Pregnancy and Childbirth 2013 13:206.

\section{Submit your next manuscript to BioMed Central and take full advantage of:}

- Convenient online submission

- Thorough peer review

- No space constraints or color figure charges

- Immediate publication on acceptance

- Inclusion in PubMed, CAS, Scopus and Google Scholar

- Research which is freely available for redistribution 